\title{
Low-Frequency Electromagnetic Field Exposure Enhances Extracellular Trap Formation by Human Neutrophils through the NADPH Pathway
}

\author{
Lieke A. Golbach ${ }^{a}$ Marleen H. Scheer ${ }^{a}$ Jan J.M. Cuppen ${ }^{b}$ Huub Savelkoul ${ }^{a}$ \\ B.M. Lidy Verburg-van Kemenade ${ }^{a}$ \\ ${ }^{a}$ Department of Cell Biology and Immunology, Wageningen University, Wageningen, and \\ ${ }^{b}$ Faculty of Electrical Engineering, Eindhoven University of Technology, Eindhoven, The Netherlands
}

\section{Key Words}

Electromagnetic fields $\cdot$ Immune responses $\cdot$ Low-frequency electromagnetic fields · NADPH oxidase - Neutrophil extracellular traps · Oxidative burst · Reactive oxygen species

\begin{abstract}
Low-frequency (LF) electromagnetic fields (EMFs) are abundantly present in modern society, and the potential biological consequences of exposure to these fields are under intense debate. Immune cells are suggested as possible target cells, though a clear mechanism is lacking. Considering their crucial role in innate immune activation, we selected an ex vivo exposure set-up with human neutrophils to investigate a possible correlation between neutrophil extracellular trap (NET) formation and LF EMF exposure. Our study shows that formation of NETs is enhanced by LF EMF exposure. Enhanced NET formation leads to increased antimicrobial properties as well as damage to surrounding cells. We found that LF-EMF-induced NET formation is dependent on the NADPH oxidase pathway and production of reactive oxygen species. Additionally, LF EMF exposure does not influence autophagy and PAD4 activity. Our study provides a mechanism by which exposure to LF EMFs could influence the innate immune system.

(c) 2015 S. Karger AG, Basel
\end{abstract}

\section{Introduction}

Environmental exposure to low-frequency (LF) electromagnetic fields (EMFs) produced by household appliances, communication equipment and power lines is increasing. Consequently, societal concern regarding potential adverse health effects of chronic exposure to LF EMFs is rising [1]. Reported effects of LF EMFs on biological systems range from harmful interactions [2] to beneficial effects [3]. No precise mechanism of action of LF EMFs has yet been elucidated, although immune cell activation through receptor interactions, calcium mobilisation and free radical production has been suggested [4]. Mechanistic studies to elucidate the biological response to LF EMF exposure so far mainly focused on macrophages and monocytes [3-5]. Neutrophils, on the other hand, were not studied extensively in this context. Neutrophils, however, fulfil a key role in the innate immune system by rapid eradication of invading pathogens via several strategies. They quickly migrate towards an infection and dominate the infected site already after a couple of minutes [6]. They are highly reactive, mobile and sensitive cells, which makes them putative targets to investigate possible cell modulation by LF EMF exposure [4].

Initially, phagocytosis of pathogens and degranulation of lytic enzymes were considered to be the only two anti-

\begin{tabular}{|c|c|}
\hline KARGER 125 & $\begin{array}{l}\text { (c) } 2015 \text { S. Karger AG, Basel } \\
1662-811 X / 15 / 0075-0459939.50 / 0\end{array}$ \\
\hline $\begin{array}{l}\text { E-Mail karger@karger.com } \\
\text { www.karger.com/jin }\end{array}$ & $\begin{array}{l}\text { This is an Open Access article licensed under the terms of the } \\
\text { Creative Commons Attribution-NonCommercial 3.0 Un- } \\
\text { ported license (CC BY-NC) (www.karger.com/OA-license), } \\
\text { applicable to the online version of the article only. Distribu- } \\
\text { tion permitted for non-commercial purposes only. }\end{array}$ \\
\hline
\end{tabular}

Dr. Lidy Verburg-van Kemenade

Department of Cell Biology and Immunology Wageningen University

NL-6708 WD Wageningen (The Netherlands)

E-Mail lidy.vankemenade@wur.nl 
microbial strategies neutrophils used, but in 2004 a third special defence mechanism was described: neutrophil extracellular trap (NET) formation [7]. During NET formation, nuclear DNA is mixed with antimicrobial proteins to release an antimicrobial extracellular trap that captures and destroys extracellular microbes. Recent studies showed the importance of NADPH oxidase activity and consequential reactive oxygen species (ROS) formation that triggers dissociation of the peptide complexes, which contain the antimicrobial proteins $[8,9]$. Subsequently, peptidylarginine deiminase 4 (PAD4) [10] decondensates the chromatin, followed by disintegration of the nuclear envelop through autophagy to facilitate intermingling of these antimicrobial peptides with chromosomal DNA [11]. These findings underscore that NET formation involves specific signal transduction pathways and is tightly regulated to ensure a well-balanced innate immune response. NET formation requires an active NADPH oxidase complex to generate large amounts of superoxide anion radicals $\left(\mathrm{O}_{2}^{-}\right)$that are rapidly dismutated to hydrogen peroxide $\left(\mathrm{H}_{2} \mathrm{O}_{2}\right)$. Patients with chronic granulomatous disease highlight the importance of functional NADPH oxidase activity, since these patients fail to maintain phagocytosis or generate NETs [12]. Even though NET formation involves activation of intracellular signalling pathways that have been linked to the effects of LF EMFs, such as ROS production and NADPH oxidase activation $[13,14]$, a correlation between NET formation by neutrophils and LF EMF exposure has not been studied yet. In an ex vivo experimental set-up we show that LF EMF exposure is able to enhance NET formation in neutrophils for which the NADPH pathway and subsequent ROS production are essential. These NETs are able to capture and kill bacteria, as well as damage epithelial cells, thereby indicating that NET formation by neutrophils is a vital but also delicately regulated process, which may be modulated by LF EMF exposure. Our study provides a reliable mechanism by which exposure to LF EMFs could influence the innate immune system.

\section{Material and Methods}

\section{Neutrophil Isolation and NET Formation}

Blood of healthy donors, which were not taking any medication, was used. Ethical permission for all donations was obtained from a local ethical committee (No. NL.44545.091.13) and a written consent was obtained from each donor. Blood was layered onto a discontinuous Percoll density gradient $(1,079$ and $1,098 \mathrm{~g} / \mathrm{ml})$ and centrifuged at $1,200 \mathrm{~g}$ for $10 \mathrm{~min}$. Red blood cells were lysed and the remaining neutrophils were washed with RPMI (the de- tailed method is outlined in online suppl. note 1; for all online suppl. material, see www.karger.com/doi/10.1159/000380764). Cell purity was $\sim 98 \%$ or higher determined by flow cytometry. To induce NET formation, $0.1 \times 10^{6}$ neutrophils were seeded in black/ clear 96-well plates and left to adhere for $1 \mathrm{~h}$ with or without diphenyleneiodonium (DPI) chloride $(0.5$ and $5.0 \mu \mathrm{M})$, wortmannin $(100 \mathrm{nM}), \mathrm{Cl}$-amidine $(200 \mu \mathrm{M})$ or cytochalasin D $(20 \mu \mathrm{M})$. NET formation was induced by the addition of $50 \mathrm{nM}$ phorbol myristate acetate (PMA). Cells were exposed to either $300 \mu \mathrm{T}$ LF EMF or sham. Extracellular DNA was quantified with SYTOX Green 1, 2 , 3 and $4 \mathrm{~h}$ after stimulation ( $1 \mu \mathrm{M}, 5 \mathrm{~min})$ with a spectrofluorometer (ex. $504 \mathrm{~nm} / \mathrm{em} .515 \mathrm{~nm}$ ). $\mathrm{O}_{2}^{-}$production was determined $60 \mathrm{~min}$ after stimulation with $1 \mathrm{mg} / \mathrm{ml}$ nitroblue tetrazolium, as described earlier [15].

\section{RNA FISH of Neutrophils and Bacteria}

LF EMF exposure and sham neutrophils $\left(0.2 \times 10^{6}\right)$ on glass slides were stimulated with $50 \mathrm{nM}$ PMA for $3 \mathrm{~h}$. Living cells were stained with $1 \mathrm{ng} / \mathrm{ml} \mathrm{Hoechst} \mathrm{and} 1 \mu \mathrm{M}$ SYTOX Green for $5 \mathrm{~min}$. For immunohistochemistry, Escherichia coli JM109 (multiplicity of infection: 6) were added after 30 min of PMA stimulation. After $3 \mathrm{~h}$, cells and bacteria were fixed in $4 \%$ paraformaldehyde and stained with 16S-Alexa $488(1 \mu \mathrm{g} / 100 \mu \mathrm{l})$ and $0.5 \mu \mathrm{M}$ SYTOX Green (detailed in online suppl. note 2). Images were taken with an EVOS $^{\circledR}$ FL System and Leica LSM 510.

\section{Bacterial Killing Assay by NETs}

Neutrophils were stimulated with medium or $50 \mathrm{nM}$ PMA. After $4 \mathrm{~h}$, NETs were removed by vigorous shaking for $5 \mathrm{~min}$ at $300 \mathrm{rpm}$ and the supernatant was centrifuged for $5 \mathrm{~min}$ at $500 \mathrm{~g}$. To determine bacterial killing by NETs, $0.5 \times 10^{6}$ E. coli JM109 were incubated for $3 \mathrm{~h}$ in either RPMI-1640, supernatant from unstimulated neutrophils (Sup) or supernatant from stimulated neutrophils containing NETs. PMA concentrations were kept equal for each condition $(50 \mathrm{nM})$. To release captured bacteria, after $3 \mathrm{~h}$ samples were incubated with $100 \mathrm{U} / \mathrm{ml} \mathrm{DNase}$ I for $15 \mathrm{~min}$. Serial dilutions in sterile PBS were placed on lysogeny broth agar plates and the surviving bacteria were enumerated and normalised to the bacterial survival in RPMI-1640. Experiments were performed with 3 independent donors in three independent experiments. Due to large variations between individual experiments with the same experimental outcomes, only one of the three experiments is presented with mean colony-forming units $(\mathrm{CFU}) \pm$ SEM of five individual agar plates.

Endothelial Cell Viability and Caspase-3 and -7 Activities after NET Treatment

Cells from the human gingival carcinoma cell line Ca9-22 were seeded in 96-well plates to reach 90\% confluence. RPMI-1640, supernatant or NETs were added. Cell viability was determined by MTS tetrazolium formation (P3580 Promega protocol) and apoptosis induction by caspase- 3 and -7 activities (Caspase-Glo ${ }^{\circledR} 3 / 7$ assay, Promega) at the indicated time points.

\section{LF EMF Exposure System}

Cell exposure was performed with a custom-made exposure system (Immunent BV, Veldhoven, The Netherlands), which fits inside a standard cell culture incubator to ensure optimal cell culture conditions with $37 \pm 0.2^{\circ} \mathrm{C}$ and $5 \% \mathrm{CO}_{2}$. An irregular combination of four block waves, described previously [16], with frequencies of $320,730,880$ and $2,600 \mathrm{~Hz}$ was applied at a magnetic 
Fig. 1. LF EMF exposure enhances NET formation. a Human neutrophils were stimulated with $50 \mathrm{nM}$ PMA $(\mathbf{O} / \mathbf{\Delta})$ or left unstimulated $(O / \triangle)$ in the absence (sham; $\mathrm{O} / \mathrm{O})$ or presence of $\operatorname{LF} \operatorname{EMF}(\boldsymbol{\Delta} / \triangle)$. Group mean (line) of all 9 individual donors (dots), * $\mathrm{p}<0.05,{ }^{* *} \mathrm{p}<0.01$. b Caspase- 3 and -7 activity. Group means (lines) of all 4 individual donors (dots). c Microscopic image of extracellular DNA (SYTOX Green) and nuclear DNA (Hoechst blue; see online version for colours). Scale bar $=$ $100 \mu \mathrm{m}$.

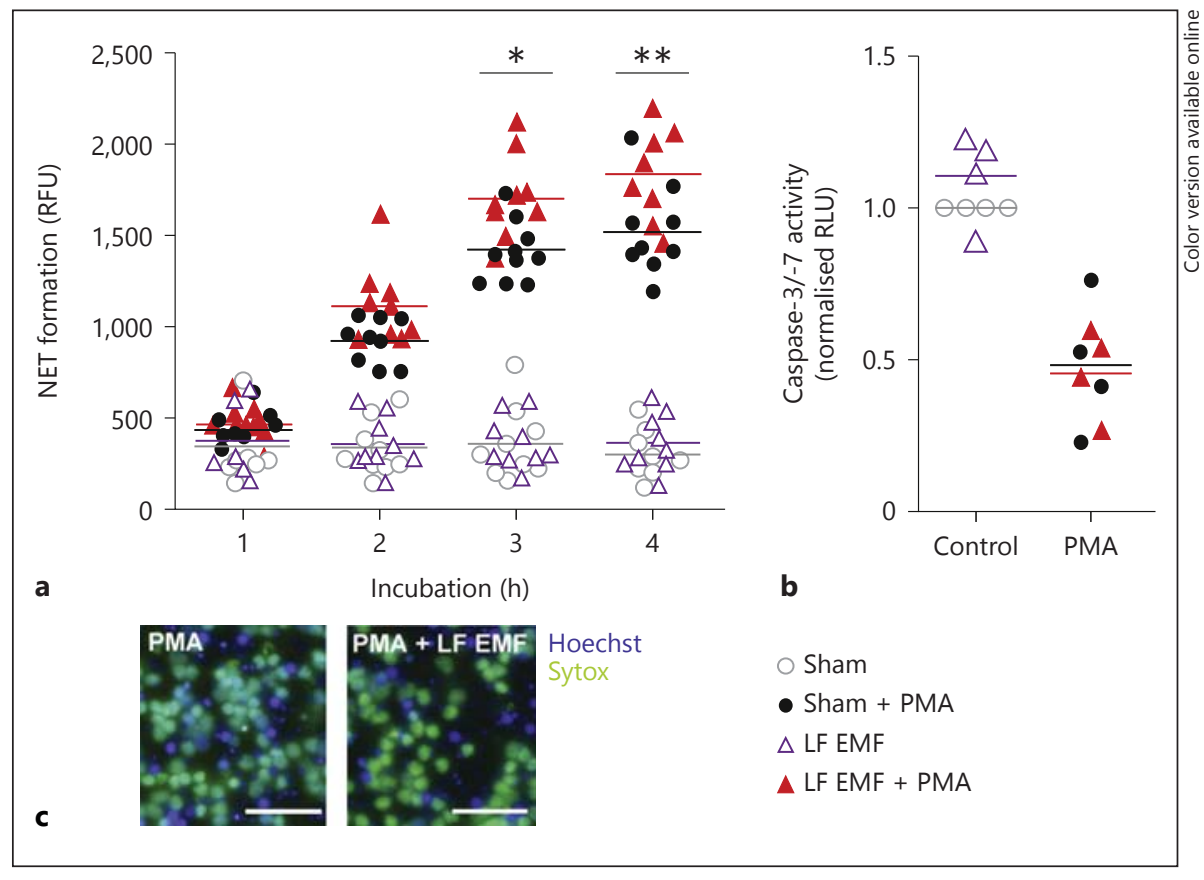

field intensity of $300 \mu \mathrm{T}$. Sham treatment consisted of identical culture conditions with a unenergised coil in a second identical incubator.

\section{Statistics}

Data were analysed using GraphPad Prism 5.0 (GraphPad Software). Gaussian distribution was checked, and differences between sham and LF EMF groups were analysed using repeated-measure two-way ANOVA with post hoc Bonferroni correction. Differences between CFU were analysed using one-way ANOVA with post hoc Bonferroni correction. The numbers of individual donors (n), group means and SEM are indicated in the legend. Statistical significance was accepted at $\mathrm{p}<0.05$.

\section{Results and Discussion}

Effect of LF EMF Exposure on ex vivo NET Formation Human neutrophils were isolated from the blood of healthy volunteers $(n=9)$ and exposed to LF EMFs or sham in the absence or presence of $50 \mathrm{nM}$ PMA, a potent NET formation inducer. Although mean total exposure during a normal day does not get above $5 \mu \mathrm{T}$ [17], we selected $300 \mu \mathrm{T}$ as it exceeds the general exposure safety limit of $200 \mu \mathrm{T}$, but is well below the occupational exposure limit of $1 \mathrm{mT}$ [18]. After 1, 2, 3 and $4 \mathrm{~h}$, the extracellular DNA content was quantified with SYTOX Green. Figure la shows that NET formation induced by PMA significantly increased by $~ 25 \%$ after $4 \mathrm{~h}$ if the cells were simultaneously exposed to LF EMFs. Both the LF EMF- and sham-exposed cells showed clear cloud-like structures after selective DNA staining (fig. 1c). Without PMA stimulation, LF EMF was not able to induce NET formation by itself.

To eliminate the possibility that increased fluorescence intensity was the result of an alternative pathway leading to apoptotic cells with a compromised membrane, caspase- 3 and -7 activity were determined after LF EMF exposure (fig. 1b). Caspase cleavage is not involved in NET formation and was shown to be actively blocked by PMA stimulation [11]. These results exclude the potential induction of apoptosis by LF EMF exposure, which has been suggested previously $[2,19]$.

\section{Consequences of LF EMF-Enhanced NET Formation in vitro}

The prime role of NET formation by neutrophils is to combat invading pathogens. They trap and immobilise pathogens to prevent spreading towards other tissues and facilitate killing by other immune cells, such as macrophages. Moreover, pathogens can be killed by the antimicrobial peptides bound to the DNA strands [7]. As LF EMF enhanced NET release by stimulated neutrophils, we investigated the effect of these NETs on bacterial killing. There are various assays to investigate the killing capacity of NETs. Most research groups block phagocytosis with a high concentration of cytochalasin $\mathrm{D}$, to exclusively investigate killing by NET formation. However, cyto- 


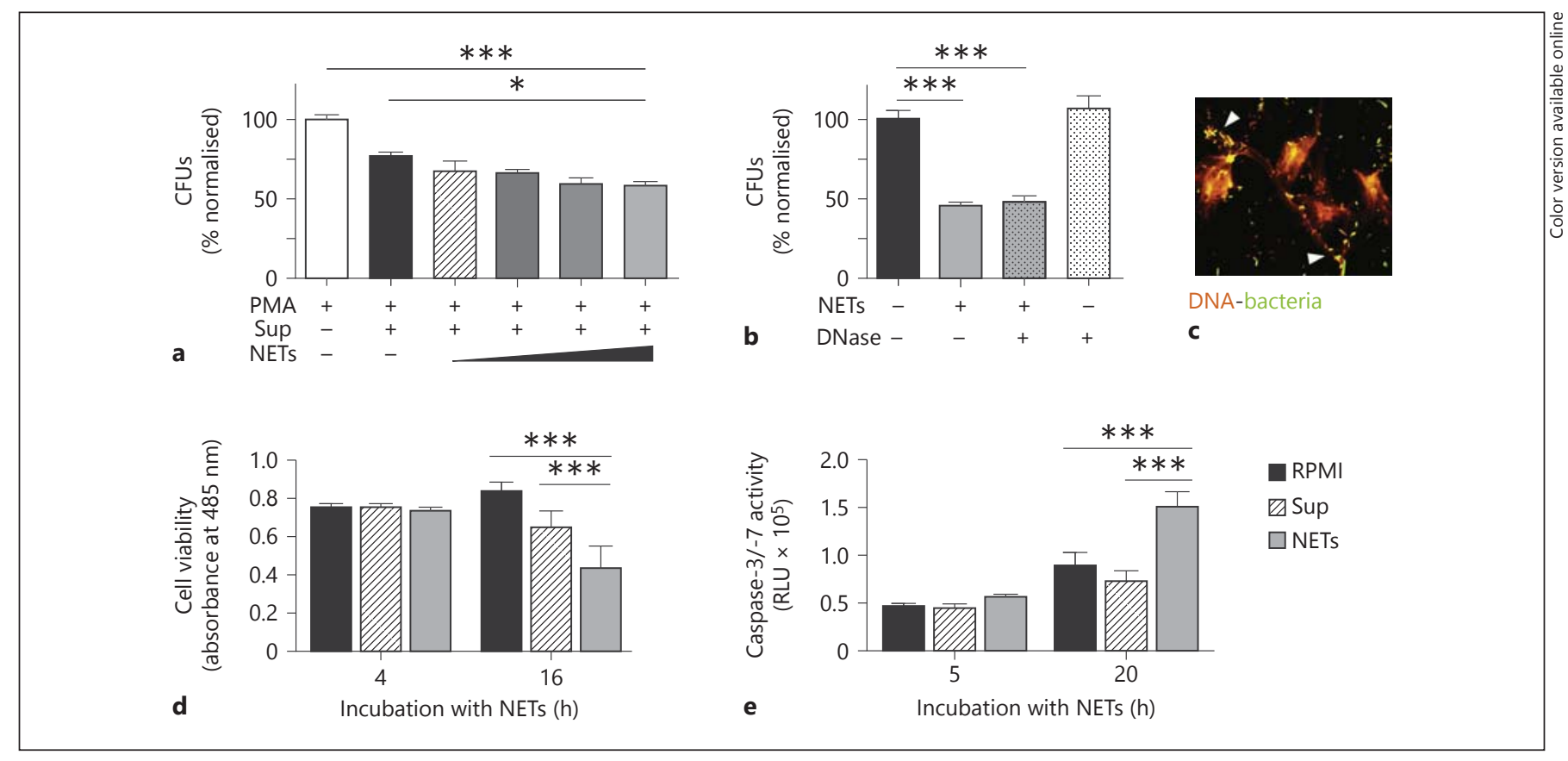

Fig. 2. Killing of microbes and damage of oral epithelial cells by NETs. Bacterial survival after $3 \mathrm{~h}$ of incubation with medium, supernatant of unstimulated neutrophils (Sup) or NETs in increasing concentrations (a) and surviving colonies after DNase treatment (b). Graphs show representative data from three independent experiments. Mean CFU \pm SEM of five individual agar plates. $c$ RNA FISH of bacteria (green) trapped in DNA filaments (orange; see

chalasin $\mathrm{D}$ has been proven to reduce or even completely prevent NET formation $[8,20]$. On the other hand, LF EMF exposure is linked to reduced bacterial growth [21], which would make it difficult to distinguish between the effect of EMF on neutrophils or bacteria. Therefore, we adopted a functional method that involves the isolation of NETs from neutrophils and subsequent incubation with bacteria [22]. This protocol allowed us to solely investigate bacterial killing upon various concentrations of NETs. As shown in figure $2 a$, the 3-hour incubation of bacteria with NETs significantly reduced subsequent bacterial survival in a concentration-dependent manner compared to medium control. Fluorescence in situ hybridisation showed bacterial entrapment in the released DNA threads of the neutrophils (fig. 2c). Furthermore, complete digestion by DNase I did not significantly increase the amount of CFUs (fig. 2b), demonstrating that released NETs do not only entrap but also kill microbes. Together, these data show that increasing amounts of NETs correlate with decreased bacterial survival. This implies that LF-EMF-enhanced NET formation is capable of eliminating more invading pathogens. online version for colours). d MTS formation activity in oral epithelial cells after incubation with RPMI, supernatant (Sup) or NETs. e Caspase- 3 and -7 activity by oral epithelial cells after incubation with RPMI, supernatant (Sup) or NETs. Means \pm SEM of quadruplicate measurements of 2 independent donors, ${ }^{*} \mathrm{p}<0.05$, *** $\mathrm{p}<0.001$.

However, NET formation is a double-edged sword, since the cytotoxic effects of NETs are not limited to foreign pathogens. NETs represent a diverse range of cryptic self-epitopes that can lead to autoimmune diseases like systematic lupus erythematosus [23] and arthritis [24]. Furthermore, collateral damage to the host's own endothelial and epithelial cells was also described [22]. Our data support this report, since we were able to show cell damage as a result of NET release. We visualised cellular damage by incubating a monolayer of oral epithelial cells with isolated NETs. After $4 \mathrm{~h}$, cell viability measured by the MTS assay was not affected, but after $16 \mathrm{~h}$ cell viability was significantly reduced (fig. 2d). Furthermore, already after a 5-hour incubation with NETs, increased caspase- 3 and -7 activity was detected in epithelial cells (fig. 2e). After $20 \mathrm{~h}$, caspase activity was significantly increased compared to medium or the supernatant of unstimulated neutrophils, showing that enhanced NET formation leads to apoptosis of epithelial cells. This indicates that enhanced NET formation by LF EMF is a risky strategy that may contribute to microbial killing as well as increased host cell damage. 


\section{Molecular Mechanism of LF EMF Increased NET}

\section{Formation}

PMA (dose-dependent up to $15 \mathrm{nM}$, online suppl. fig. 1a) is a potent inducer of NET formation and increasing the PMA concentration to $100 \mathrm{nM}$ did not induce more NETs (online suppl. fig. 1b). PMA mimics a pathogenic stimulation in neutrophils by intracellular protein kinase $C$ activation [25]. Interestingly, even at $50 \mathrm{nM}$ of PMA, LF EMF exposure showed a synergistic effect on NET formation (fig. 1a), suggesting that LF EMF modulates the PMA-induced signalling pathway downstream of protein kinase $\mathrm{C}$ activation.

To further unravel the molecular mechanism by which LF EMF is increasing PMA-stimulated NET formation, we investigated possible signalling pathways preceding actual NET release. Within 30 min after PMA stimulation, neutrophils undergo profound and significant morphological changes, characterised by immediate cell flattening, cell adherence and massive vacuolisation [26]. This process is an interplay between autophagy, the cytoskeleton, superoxide production and histone citrullination [11], and by using selective inhibitors for each of these cellular pathways, contributing signalling pathways were identified. The importance of a functional cytoskeleton has already been emphasised shortly after the first discovery of NETs [20], but a recent report uncovered the physiological mechanisms. The actin cytoskeleton acts as a temporal store for cytoplasmic neutrophil elastase to gradually increase the nuclear concentration of elastase, eventually leading to histone citrullination [8]. We found that cytochalasin $\mathrm{D}$ was able to block this process under LF EMF and sham conditions, which shows that LFEMF-enhanced NET formation also requires an active cytoskeleton.

When autophagy was inhibited with PI3K inhibitor wortmannin, only a small reduction in NET formation was observed (fig. 2d). These data must be interpreted with caution, as altered NET formation by wortmannin is difficult to detect with cell-impermeable dyes like SYTOX. Upon autophagy inhibition, the neutrophils undergo a type of cell death characterised by hallmarks of apoptosis, leading to membrane rupture [11].

Further downstream of the NET formation pathway is PAD4 activation. Histone citrullination by PAD4 is considered to promote NET formation through chromatin decondensation, thereby facilitating intermingling of antimicrobial peptides with chromosomal DNA. PAD4 activity is calcium dependent and crucial for NET formation induced by living bacteria [10] and the proinflammatory cytokine TNFa [27]. However, Neeli et al. [25] showed that PMA induces activation of protein kinase $\mathrm{Ca}$, which inhibits PAD4 histone citrullination without interfering with the capacity of the cell to release NETs. Interestingly, this research group also demonstrated that stimulation of neutrophils with PMA and calcium ionophore led to more extensive NET release. We hypothesised that if LF EMF enhances PAD4 activity, resulting in increased NET formation, this would be inhibited with a PAD4 inhibitor. When neutrophils were pre-incubated with $200 \mu \mathrm{M}$ of the PAD4 inhibitor $\mathrm{Cl}$-amidine, no changes in NET formation were observed, indicating that LF EMF does not enhance PAD4 activity. These results are further corroborated by the ability of PAD4 overexpression to induce NET formation even in non-immune cells [28]. Therefore, if LF EMF exposure increases PAD4 activity, LF EMF exposure alone would have induced enhanced NET formation, which we did not detect at any of the indicated time points.

Role of NADPH Oxidase in Enhanced NET Formation

Previous studies have established that PMA-induced NET formation requires an active NADPH oxidase complex to generate large amounts of $\left(\mathrm{O}_{2}^{-}\right)$that are rapidly converted inside the cell to hydrogen peroxide $\left(\mathrm{H}_{2} \mathrm{O}_{2}\right)$ by dismutation. The crucial role of NADPH oxidase in NET formation is illustrated in chronic granulomatous disease patients with dysfunctional NADPH oxidase activity, as they fail to generate NETs [12]. In addition, pharmacological inhibition of NADPH oxidase activity by DPI in healthy neutrophils resulted in complete inhibition of NET formation. Oxidative stress with free radical production is one of the proposed mechanisms by which LF EMF exposure affects cellular behaviour $[4,13]$. Neutrophils exposed to $50-\mathrm{Hz}$ EMFs showed increased ROS and free radical production [13]. We used DPI to investigate if LF EMF exposure influenced NET formation in an $\mathrm{NADPH}$-dependent manner (fig. 3b). In accordance with other studies, DPI completely blocked PMA-stimulated NET formation. Moreover, LF-EMF-enhanced NET formation was also completely abolished if the neutrophils were pre-incubated with DPI. This indicates that LFEMF-enhanced NET formation acts via an NADPH-oxidase-dependent mechanism and does not activate an alternative pathway, as found for uric acid [29] or ionomycin-induced NET formation [9]. These results were further substantiated by analysis of $\mathrm{O}_{2}^{-}$production $60 \mathrm{~min}$ after PMA stimulation, which showed a significant increase in $\mathrm{O}_{2}^{-}$production following LF EMF exposure compared to PMA stimulation alone (fig. 3c). For monocytes [30] and macrophages [5], small increases in ROS 


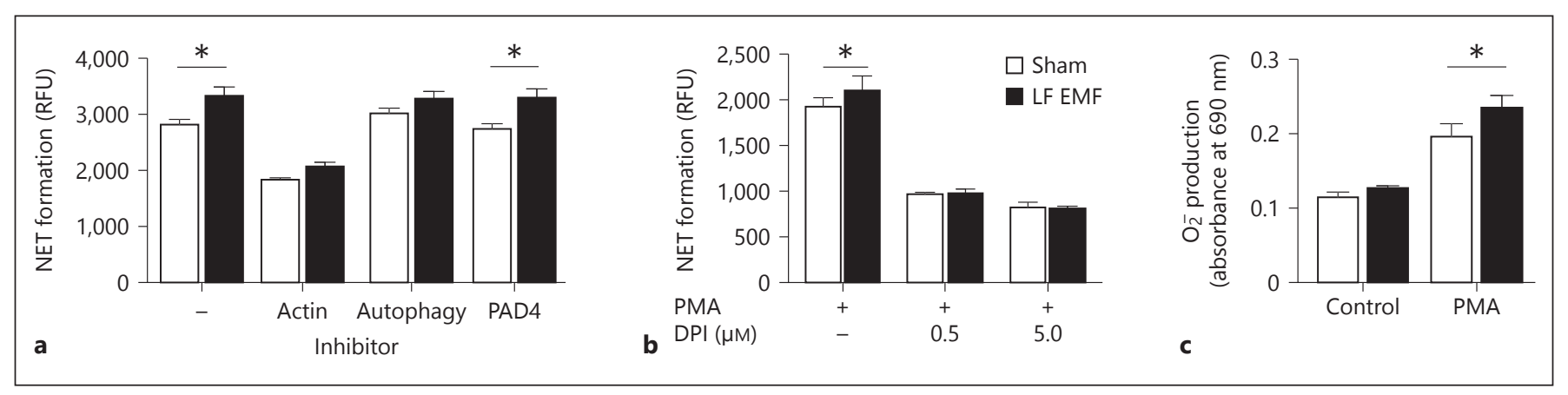

Fig. 3. Exposure to LF EMF enhances NET formation via NADPH oxidase and ROS. a NET formation induced by PMA (-) was blocked with the use of the indicated inhibitors. Means \pm SEM of 3 independent donors. b Neutrophils stimulated with 50 nM PMA, supplemented with $0,0.5$ or $5.0 \mu \mathrm{M}$ DPI. Means \pm SEM of 6 independent donors. c Intracellular $\mathrm{O}_{2}^{-}$production by neutrophils. Means \pm SEM of four independent donors, ${ }^{*} \mathrm{p}<0.05$. production, in the range of 1.2 - to 1.5 fold, were observed when LF EMF was applied to the cells. In these studies, activation of the NADPH oxidase complex by PMA was no prerequisite to achieve significant differences in ROS production. We observed a different effect, since stimulation of the intracellular pathway appeared to be required. One mechanism for increased ROS production by LF EMF could be enhanced NADPH oxidase activity or elevated protein expression. The backbone of this enzyme is the cell membrane-bound cytochrome b558, which consists of two subunits gp91phox and p22phox. Frahm et al. [5] showed that while 12-O-tetradecanolyphorbol13-acetate, an analogue of PMA, induced a transient increase in gp91phox protein expression after $2 \mathrm{~h}, 50-\mathrm{Hz}$ EMF exposure was able to achieve a similar up-regulation already after $15 \mathrm{~min}$. Since the effect of LF EMF was only detectable after stimulation with PMA, priming of neutrophils could occur. This phenomenon is also observed when neutrophils are exposed to a low concentration of granulocyte-macrophage colony-stimulating factor before oxidative burst stimulation [31]. The neutrophils are shortly brought to a state of enhanced responsiveness that is reflected by increased activity upon further addition of a potent stimulus, like PMA. We, therefore, suggest that the synergistic effect of LF EMF and PMA might be the result of short-term priming of neutrophils by LF EMF exposure.

\section{Conclusion}

This is the first study to show that LF EMF exposure is able to significantly enhance NET formation ex vivo. Cellular activation by PMA was needed, since LF EMF exposure alone was not able to promote NET formation. The pathways involved in PMA-stimulated NET formation are partly known [32]; with the use of selective pharmacological inhibitors, we demonstrated that the NADPH pathway is crucial for LF-EMF-enhanced NET formation, possibly by upregulated ROS production. These data provide a basic mechanism of action on immune cells to explain potential health effects of LF EMFs generated by household appliances and power lines.

\section{Acknowledgements}

This study was financially supported by ZonMw (grant No. 85300006).

\section{References}

1 Feychting M, Ahlborn A, Kheifets L: EMF and health. Annu Rev Public Health 2005;26:165189.

2 Wolf FI, Torsello A, Tedesco B, Fasanella S, Boninsegna A, D’Ascenzo M, Grassi C, Azzena GB, Cittadini A: $50-\mathrm{Hz}$ extremely low frequency electromagnetic fields enhance cell proliferation and DNA damage: possible in- volvement of a redox mechanism. Biochim Biophys Acta 2005;1743:120-129.

-3 Akan Z, Aksu B, Tulunay A, Bilsel S, InhanGarip A: Extremely low-frequency electromagnetic fields affect the immune response of monocyte-derived macrophages to pathogens. Bioelectromagnetics 2010;31: 603-612.

\footnotetext{
4 Simko M, Mattsson MO: Extremely low frequency electromagnetic fields as effectors of cellular responses in vitro: possible immune cell activation. J Cell Biochem 2004;93:83-92.

5 Frahm J, Mattsson MO, Simko M: Exposure to ELF magnetic fields modulate redox related protein expression in mouse macrophages. Toxicol Lett 2010;192:330-336.
} 
6 Nathan C: Neutrophils and immunity: challenges and opportunities. Nat Rev Immunol 2006;6:173-182.

7 Brinkmann V, Reichard U, Goosmann C, Fauler B, Uhlemann Y, Weiss DS, Weinrauch Y, Zychlinsky A: Neutrophil extracellular traps kill bacteria. Science 2004;303:15321535.

8 Metzler KD, Goosmann C, Lubojemska A, Zychlinsky A, Papayannopoulos V: A myeloperoxidase-containing complex regulates neutrophil elastase release and actin dynamics during NETosis. Cell Rep 2014;8:883-896.

-9 Parker H, Dragunow M, Hampton MB, Kettle AJ, Winterbourn CC: Requirements for NADPH oxidase and myeloperoxidase in neutrophil extracellular trap formation differ depending on the stimulus. J Leukoc Biol 2012;92:841-849.

10 Li PX, Li M, Lindberg MR, Kennett MJ, Xiong $\mathrm{N}$, Wang YM: PAD4 is essential for antibacterial innate immunity mediated by neutrophil extracellular traps. J Exp Med 2010;207:18531862.

-11 Remijsen Q, Vanden Berghe T, Wirawan E, Asselbergh B, Parthoens E, De Rycke R, Noppen S, Delforge M, Willems J, Vandenabeele P: Neutrophil extracellular trap cell death requires both autophagy and superoxide generation. Cell Res 2011;21:290-304.

-12 Palmer LJ, Cooper PR, Ling MR, Wright HJ, Huissoon A, Chapple ILC: Hypochlorous acid regulates neutrophil extracellular trap release in humans. Clin Exp Immunol 2012;167: 261-268.

13 Poniedzialek B, Rzymski P, Nawrocka-Bogusz H, Jaroszyk F, Wiktorowicz K: The effect of electromagnetic field on reactive oxygen species production in human neutrophils in vitro. Electromagn Biol Med 2013;32:333341.

14 Rollwitz J, Lupke M, Simko M: Fifty-hertz magnetic fields induce free radical formation in mouse bone marrow-derived promonocytes and macrophages. Biochim Biophys Acta 2004;1674:231-238.

15 Choi HS, Kim JW, Cha YN, Kim C: A quantitative nitroblue tetrazolium assay for deter- mining intracellular superoxide anion production in phagocytic cells. J Immunoassay Immunochem 2006;27:31-44.

16 Bouwens M, de Kleijn S, Ferwerda G, Cuppen JJ, Savelkoul HFJ, Verburg-van Kemenade BML: Low-frequency electromagnetic fields do not alter responses of inflammatory genes and proteins in human monocytes and immune cell lines. Bioelectromagnetics 2012;33: 226-237.

17 Bolte JFB, Eikelboom T: Personal radiofrequency electromagnetic field measurements in The Netherlands: exposure level and variability for everyday activities, times of day and types of area. Environ Int 2012;48:133-142.

18 International Commission on Non-Ionizing Radiation Protection: Guidelines for limiting exposure to time-varying electric and magnetic fields ( $1 \mathrm{~Hz}$ to $100 \mathrm{khz})$. Health Phys 2010;99:818-836.

19 Pang LJ, Traitcheva N, Gothe G, Gomez JAC, Berg H: ELF-electromagnetic fields inhibit the proliferation of human cancer cells and induce apoptosis. Electromagn Biol Med 2002;21:243-248

20 Neeli I, Dwivedi N, Khan S, Radic M: Regulation of extracellular chromatin release from neutrophils. J Innate Immun 2009;1:194-201.

21 Inhan-Garip A, Aksu B, Akan Z, Akakin D, Ozaydin AN, San T: Effect of extremely low frequency electromagnetic fields on growth rate and morphology of bacteria. Int J Radiat Biol 2011;87:1155-1161.

22 Saffarzadeh M, Juenemann C, Queisser MA, Lochnit G, Barreto G, Galuska SP, Lohmeyer J, Preissner KT: Neutrophil extracellular traps directly induce epithelial and endothelial cell death: a predominant role of histones. PLoS One 2012;7:e32366.

23 Liu CL, Tangsombatvisit S, Rosenberg JM, Mandelbaum G, Gillespie EC, Gozani OP, Alizadeh AA, Utz PJ: Specific post-translational histone modifications of neutrophil extracellular traps as immunogens and potential targets of lupus autoantibodies. Arthritis Res Ther 2012;14:R25.

24 Pratesi F, Dioni I, Tommasi C, Alcaro MC, Paolini I, Barbetti F, Boscaro F, Panza F,
Puxeddu I, Rovero P, Migliorini P: Antibodies from patients with rheumatoid arthritis target citrullinated histone 4 contained in neutrophils extracellular traps. Ann Rheum Dis 2014;73:1414-1422.

25 Neeli I, Radic M: Opposition between PKC isoforms regulates histone deimination and neutrophil extracellular chromatin release. Front Immunol 2013;4:38.

26 Hakkim A, Fuchs TA, Martinez NE, Hess S, Prinz H, Zychlinsky A, Waldmann H: Activation of the RAF-MEK-ERK pathway is required for neutrophil extracellular trap formation. Nat Chem Biol 2011;7:75-77.

27 Wang YM, Li M, Stadler S, Correll S, Li PX, Wang DC, Hayama R, Leonelli L, Han H, Grigoryev SA, Allis CD, Coonrod SA: Histone hypercitrullination mediates chromatin decondensation and neutrophil extracellular trap formation. J Cell Biol 2009;184:205213.

28 Leshner M, Wang S, Lewis C, Zheng H, Chen XA, Santy L, Wang Y: PAD4 mediated histone hypercitrullination induces heterochromatin decondensation and chromatin unfolding to form neutrophil extracellular traplike structures. Front Immunol 2012;3:307.

29 Arai Y, Nishinaka Y, Arai T, Morita M, Mizugishi K, Adachi S, Takaori-Kondo A, Watanabe $\mathrm{T}$, Yamashita $\mathrm{K}$ : Uric acid induces NADPH oxidase-independent neutrophil extracellular trap formation. Biochem Biophys Res Commun 2014;443:556-561.

30 Lupke M, Rollwitz J, Simko M: Cell activating capacity of $50 \mathrm{~Hz}$ magnetic fields to release reactive oxygen intermediates in human umbilical cord blood-derived monocytes and in Mono Mac 6 cells. Free Radic Res 2004;38: 985-993.

31 Weisbart RH, Kwan L, Golde DW, Gasson JC: Human GM-CSF primes neutrophils for enhanced oxidative-metabolism in response to the major physiological chemoattractants. Blood 1987;69:18-21.

32 Goldmann O, Medina E: The expanding world of extracellular traps: not only neutrophils but much more. Front Immunol 2012;3: 420 